\title{
Morphological and Biomechanical Implications of Cuboid Facet of the Navicular Bone in the Gait
}

\author{
Implicaciones Morfológicas y Biomecánicas de la Faceta Cuboídea del Navicular en la Marcha
}

\author{
Eduardo Saldías ${ }^{1}$; Assumpció Malgosa ${ }^{1}$; Xavier Jordana ${ }^{1}$ \& Albert Isidro²
}

SALdíAS, E.; MALGOSA, A.; JORDANA, X. \& ISIDRO, A. Morphological and biomechanical implications of cuboid facet of the navicular bone in the gait. Int. J. Morphol., 37(4):1397-1403, 2019.

SUMMARY: The cuboid facet of the navicular bone is an irregular flat surface, present in non-human primates and some human ancestors. In modern humans, it is not always present and it is described as an "occasional finding". To date, there is not enough data about its incidence in ancient and contemporary populations, nor a biomechanical explanation about its presence or absence. The aim of the study was to evaluate the presence of the cuboid facet in ancient and recent populations, its relationship with the dimensions of the midtarsal bones and its role in the biomechanics of the gait. 354 pairs of naviculars and other tarsal bones from historical and contemporary populations from Catalonia, Spain, have been studied. We used nine measurements applied to the talus, navicular, and cuboid to check its relationship with facet presence. To analyze biomechanical parameters of the facet, X-ray cinematography was used in living patients. The results showed that about $50 \%$ of individuals developed this surface without differences about sex or series. We also observed larger sagittal lengths of the talar facet (LSAGTAL) in navicular bones with cuboid facet. No significant differences were found in the bones contact during any of the phases of the gait. After revising its presence in hominins and non-human primates, and its implication in the bipedalism and modern gait, we suggest that cuboid facet might be related with the size of talar facet and the position of the talonavicular joint. However, other factors such as geographical conditions, genetics and stressful activities probably affect its presence too.

KEY WORDS: Cuboideonavicular joint; Population variability; Talar facet; Supination movement.

\section{INTRODUCTION}

The cuboid facet of the navicular bone (CFNB), or facies articularis lateralis anterior (Manners-Smith, 1907), is a small flat surface located next to the articular cuneiform surface, in the anterolateral area of the navicular, articulating with the cuboid bone (Fig. 1).

The CFNB is not always present in all modern humans but it is usually in non-human primates. In our species, the frequency of CFNB is ranked between $20 \%$ to $70 \%$ (Manners-Smith; Trinkaus, 1975; Pablos et al., 2018). In relation to hominids, Gomberg (1981) found that all great apes developed long and narrow facets while only $20 \%$ of modern humans present this feature. Also, Sarmiento \& Marcus (2000) evaluated the phylogeny and function of the naviculars of the fossils from Olduvai, apes and recent humans. The authors found the CFNB in all hominids and apes, noticing a low presence of this facet in modern humans. This analysis includes the CFNB area of every species, demonstrating that Gorilla beringei has the most similar results with Homo sapiens. In addition, they suggest that a large combined cuneiform surface in modern humans, reflex an absent or small CFNB (Sarmiento \& Marcus).

Despite that recent investigations in new hominin fossils approach the presence of this facet (Pomeroy et al., 2017; Pablos et al.), its causes and evolution are still insufficiently known. Considering these findings, we deemed it necessary to gather more information about the occurrence of the CFNB on contemporary and archaeological collections and delve into its function. On this basis, the aim of this study is to analyze the frequency of the CFNB within the Spanish population and to know under which circumstances the CFNB is present using morphometrical and radiological studies.

\section{MATERIAL AND METHOD}

We used the left navicular bones of 354 individuals (191 males and 163 females) from archaeological and

\footnotetext{
${ }^{1}$ Unitat d'Antropologia, Departament de Biologia Animal, Biologia Vegetal i Ecologia, Universitat Autònoma de Barcelona, Barcelona, Spain.

${ }^{2}$ Orthopedic and Trauma Surgery Department, Hospital Universitari Sagrat Cor, Barcelona, Spain.
} 


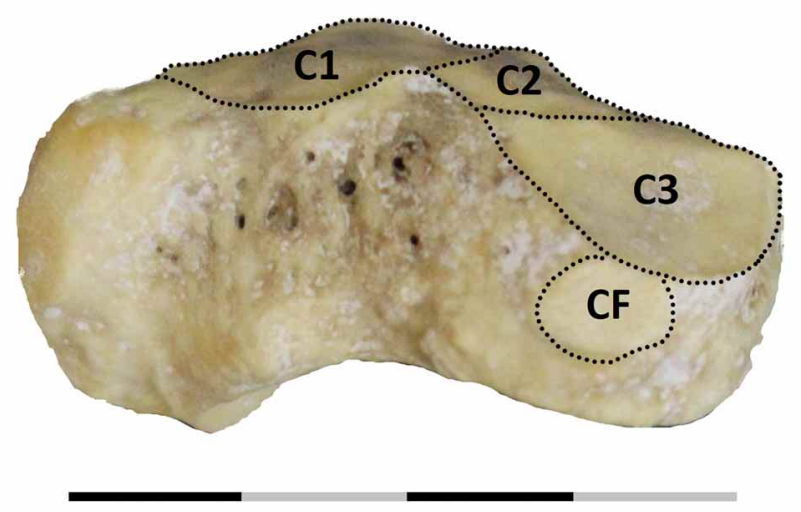

Fig. 1. Medial view of a left navicular bone. Cuneiforms and cuboid facets in discontinued lines. C1: Medial cuneiform, C2: Intermediate cuneiform, C3: Lateral cuneiform. CF: Cuboid facet. Bar scale: $4 \mathrm{~cm}$.

contemporary collections from Spain. The contemporary human remains (244) come from the documented collections of the Universidad de Granada, Universitat Autònoma de Barcelona and the Universidad Complutense of Madrid. The ancient remains (110) come from archaeological contexts in Catalonia belonging to the necropolis of the Esglésies de Sant Pere, Casserres and Castell de Termens (Table I). Only well preserved specimens were analyzed.

We considered the CFNB as a flat anterolateral surface next to the third cuneiform facet of the navicular bone (Fig. 1), which can vary in form, extension or breadth. An intra and inter-observer analysis for CFNB identification on 39 individuals from the UAB Faculty of Medicine collection was applied. The general frequency of the presence of the CFNB was obtained, considering the sex of the individuals and their corresponding collections. The eventual statistical differences were tested by means of the chisquared test.

To check if the dimensions of the talar bones influence the CFNB presence, nine metric variables were measured (Fig. 2). We considered two angles from the talar (1. Hori- zontal angle of the neck NECKANG and 2. Angle of torsion of the talar head TORSANG), and seven lineal measurements from different tarsal bones: two from talar (3. Head length LHEADT and 4. Head breadth BHEADT), two from navicular (5. Maximum length of the talar facet LMAXTAL and 6. Sagittal length of the talar facet LSAGTAL) and three from cuboid (7. Length LCUB, 8. Height HCUB and 9. Breadth BCUB).

To test the replicability, the intra observer error in the osteometric measurements was checked by one of the authors (ES) in approximately $10 \%$ of the whole collection using the absolute and relative technical error of measurement test (TEM). We applied a two-way ANOVA analysis in one ancient and one contemporary series (Granollers) to study the possible effects caused by two factors (sex and CFNB occurrence) in the osteometric measurements.

Finally, the CFNB of the navicular was analyzed under biomechanical parameters. The presence or absence of the CFNB was evaluated in eighty-four patients without midtarsal pathologies from the Hospital Universitari Sagrat Cor from Barcelona (HUSC) using CT scans. Randomly, three patients with the CFNB and two without it were chosen to check the eventual contact between the navicular and cuboid bones in each phase of the step. The complete step was studied under X-ray cinematography (sagittal view) using a Canon Inc. CXDI Controller RF, EC: $2.00 \mathrm{~mm}, \mathrm{C}$ : 500, A: 1500 and with a zoom of $160 \%$.

\section{RESULTS}

Considering the morphoscopic exam, the intra observer analysis did not show any differences between the first and the second observation and the interobserver analysis yielded the same results between the researchers. The CFNB frequency of the whole sample was $52.7 \%$, being

Table I. Number of individuals used from the six skeletal collections.

\begin{tabular}{|c|c|c|c|c|}
\hline \multicolumn{5}{|c|}{ CONTEMPORARY } \\
\hline UGR & Cemetery of San José, Granada. & 31 & 39 & 70 \\
\hline $\mathrm{UAB}$ & Cemeteries of Collserolla, Montjuic and Granollers, Barcelona province. & 28 & 21 & 49 \\
\hline $\mathrm{UCM}$ & Cemeteries of Alcorcón and Sur, Madrid. & 63 & 62 & 125 \\
\hline \multicolumn{5}{|c|}{ ARCHAEOLOGICAL } \\
\hline TER & Lleida, 18th-19th CE & 7 & 3 & 10 \\
\hline CAS & Berga, $7_{\text {th }} 9^{\text {th }} \mathrm{CE}$ & 20 & 14 & 34 \\
\hline STP & Terrassa, 4th-14th centuries CE & 42 & 24 & 66 \\
\hline TOTAL SERIES & & 191 & 163 & 354 \\
\hline
\end{tabular}

UGR (Universidad de Granada) collection; UAB (Universitat Autònoma de Barcelona) collection; UCM (Universidad Complutense de Madrid) collection; TER (Castell de Termens) series; CAS (Casserres) series; STP (Esglésies de Sant Pere) series. 
A

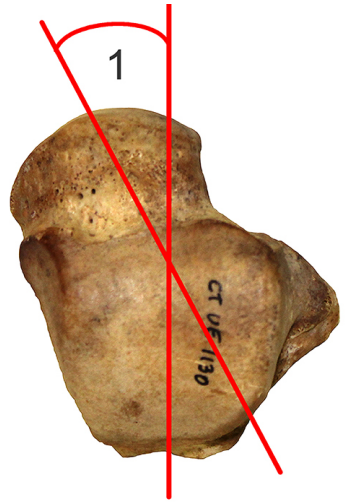

C

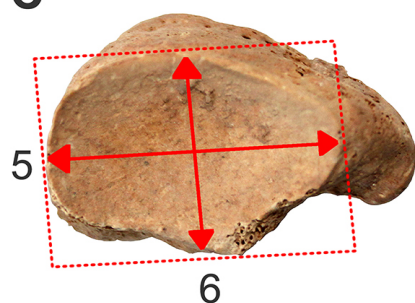

E

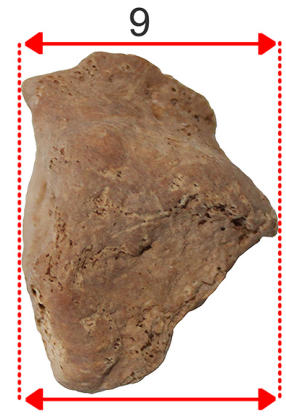

$B_{1}$

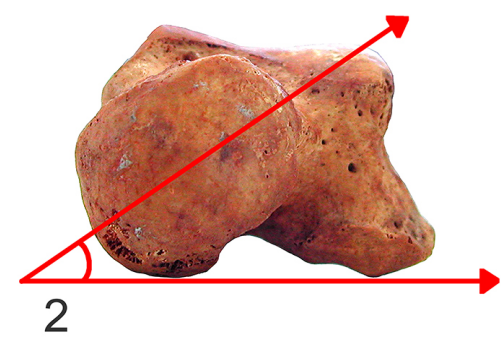

$D_{1}$

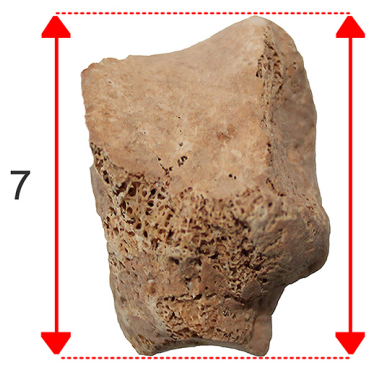

Fig. 2. The dimensions and angles are numerated according the text. A) Dorsal view of right talus. B1) - B2) Proximal view of left talus. C) Posterior view of left navicular. D1) D2) Lateral view of left cuboid. E) Plantar view of left cuboid. more frequent in the ancient series than in the contemporary ones (59\% vs $49.8 \%$ ), as well as being more frequent in women than in men $(57.1 \%$ vs $48.9 \%)$. However, no significant differences were found in relation to chronology (c2 $\mathrm{p}=0,116)$ or $\operatorname{sex}(\mathrm{c} 2 \mathrm{p}=0,132)$.

In relation to bone dimensions, the intra-observer analysis carried out in 50 feet from 30 individuals demonstrated a low rate of absolute TEM $(<0.7 \%)$ and an acceptable error in Relative TEM (Table II). Table III show the average of the seven osteometric linear dimensions and two angles measured. As expected, the two-way ANOVA analysis showed significant differences between sexes in all linear measurements, but not in the angles. Concerning the occurrence of the CFNB, the sagittal length of the talar facet (LSAGTAL) was the only metric variable showing
$\mathbf{B}_{2}$

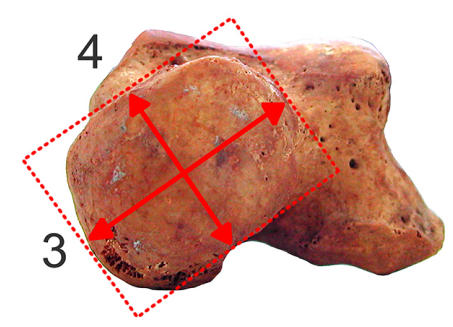

$\mathrm{D}_{2}$

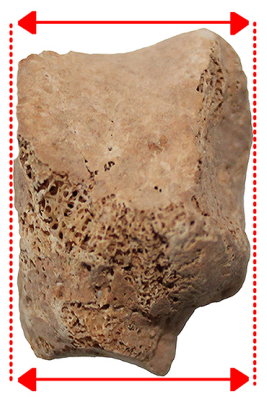

8

significant differences between naviculars with and without facets $(p<0.05)$ (Table III). Specifically, this dimension was larger in naviculars with CFNB.

To observe the effect of the contact between the navicular and cuboid bones through the CFNB during the gait, we analyzed five patients from HUSC, which were previously characterized, with (three) and without (two) CFNB through CT scans. The movements of the foot during takeoff, swing, reception of load and medium support phase were analyzed by X-ray cinematography. Both individuals with CFNB and those who do not have it, show a gap between the cuboid and navicular bones. This gap remains during all the phases of step. Therefore, none of the walk phases show significant differences between groups that explain the presence or absence of this facet (Fig. 3). 

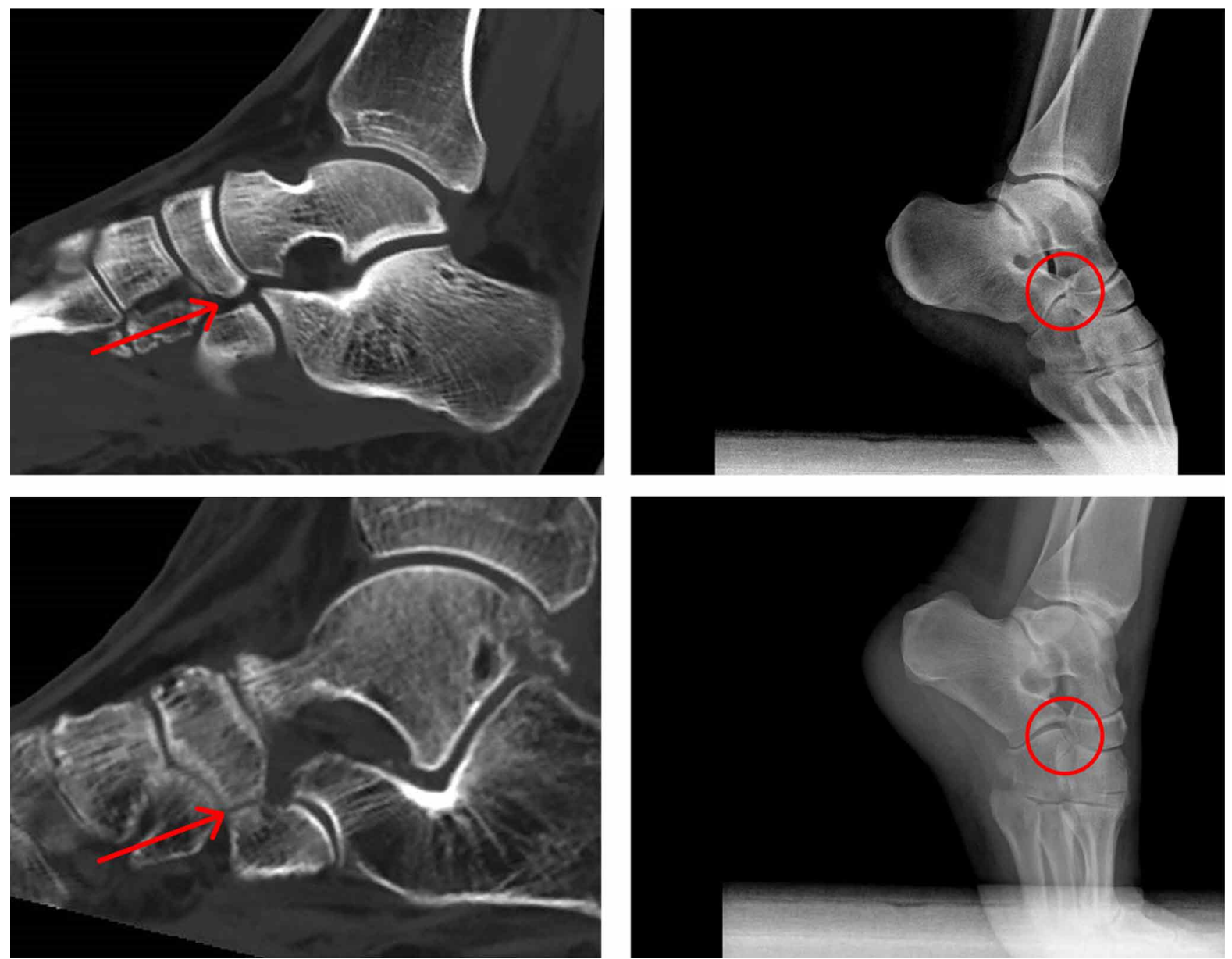

Fig. 3. Composite image. Sagittal CT slides, on the left side. X-ray cinematography freeze-images on right side. The images on the top belong to one individual with no joint between navicular and cuboid based on the CT images. The lower images are from a patient who developed cuboid facet. The images of the left shows no differences in the contact between navicular and cuboid.

\begin{tabular}{lccc}
\hline & \multicolumn{2}{c}{ INTRA-OBSERVER ANALYSIS (ES) } & \\
& Absolute TEM & Variable average value & Relative TEM \% \\
\hline NECKANG & 0.7 & 13.5 & 5.6 \\
TORSANG & 0.7 & 31.4 & 2.4 \\
LHEADT & 0.2 & 25.8 & 0.8 \\
BHEADT & 0.3 & 8.6 & 3.7 \\
LMAXTAL & 0.1 & 16.7 & 0.7 \\
LSAGTAL & 0.1 & 13.6 & 1.1 \\
LCUB & 0.0 & 24.2 & 0.3 \\
HCUB & 0.1 & 18.3 & 0.7 \\
BCUB & 0.1 & 15.9 & 1.2 \\
\hline
\end{tabular}

Table II. TEM analysis results to check the intra-observer error.

\begin{tabular}{|c|c|c|c|c|c|c|c|c|}
\hline & \multicolumn{3}{|c|}{ CFNB PRESENCE } & \multicolumn{3}{|c|}{ CFNB ABSENCE } & \multicolumn{2}{|c|}{$\begin{array}{c}\text { TWO-WAY ANOVA } \\
\text { P-value }\end{array}$} \\
\hline & $\mathbf{N}$ & Mean & SD & $\mathbf{N}$ & Mean & SD & Sex & CFNB \\
\hline NECKANG & 61 & 16.90 & 2.64 & 43 & 16.81 & 2.93 & 0.87 & 0.79 \\
\hline TORSANG & 63 & 36.74 & 5.90 & 46 & 34.58 & 5.61 & 0.47 & 0.07 \\
\hline LHEADT & 62 & 31.29 & 2.91 & 47 & 31.91 & 2.78 & 0.00 & 0.41 \\
\hline BHEADT & 64 & 21.03 & 2.32 & 44 & 21.09 & 1.96 & 0.00 & 0.70 \\
\hline LMAXTAL & 62 & 27.37 & 2.53 & 49 & 27.89 & 2.22 & 0.00 & 0.17 \\
\hline LSAGTAL & 63 & 21.61 & 2.15 & 47 & 20.80 & 1.63 & 0.00 & 0.00 \\
\hline LCUB & 67 & 36.20 & 3.45 & 48 & 36.43 & 3.59 & 0.00 & 0.86 \\
\hline BCUB & 64 & 27.34 & 2.40 & 44 & 27.15 & 2.68 & 0.00 & 0.68 \\
\hline HCUB & 65 & 23.64 & 1.94 & 47 & 23.89 & 1.82 & 0.00 & 0.69 \\
\hline
\end{tabular}

Table III. Two-way ANOVA analysis. Osteometric measurements of tarsal bones (angles in degrees and dimensions in $\mathrm{mm}$ ) by sex and CFNB occurrence. 


\section{DISCUSSION}

The prevalence of the CFNB was around $50 \%$ in the ancient and modern Spanish population. There are no significant differences among series or between sexes. Our results are similar to those found by other authors (MannersSmith; Prang, 2016; Pablos et al.), and they move away from extreme values such as those Manners-Smith $(70 \%)$ and Gomberg (1981) (20\%).

The CFNB is an almost exclusive feature of Primates but hominins do not always present it. The tuberosity of the navicular and size/disposition of cuneiform surfaces are different between our ancestors and modern humans, but shape and localization of CFNB are similar (Jungers et al., 2009; Prang). For instance, Australopitecus afarensis show a big developed tuberosity of naviculars (AL 333-36, AL 333-47) (Prang), which suggests a development of the leg musculature related with plantar-flexion movements (inversion). According to this analysis, this species has a low longitudinal arch, with a mixture of ape and human features (Prang). Moreover, these samples show a semi-lunar (AL 333-47) or round-shape CFNB (AL 333-36), which could be considered similar in form, but bigger than in modern humans. The differences in sizes could be explained by diverse locomotor patterns. However, remains of "little foot" (Clarke \& Tobias, 1995) from Sterkfontein (Stw 573, 3.5 millions of years) show unexpectedly, a navicular with a blend of human and apes traits but without CFBN. This bone developed apelike features with a narrow distance between talar and cuneiform facets and a marked angle between the lateral and intermediate cuneiform facets (Clarke \& Tobias).

About genus Homo, the navicular from $\mathrm{OH} 8$ (Homo habilis) shows a narrow and long CFNB that falls in the variability of modern humans (Kidd et al., 1996). This species probably had an arboreal capacity, with medial longitudinal structures adapted for grasping functions (navicular, talar), with terrestrial abilities (large plantar process of the cuboid), as an adapted longitudinal arch. Concerning Neanderthals, the frequency of CFNB moves from $71.4 \%$ (Trinkaus et al., 2017) to $35.7 \%$ (Pablos et $a l$.). It is possible that the presence of CFNB were due to robust/broad size of the Neanderthal and the expanded tuberosity for the attachment of plantar calcaneus-navicular ligament and tibialis posterior muscle insertion (Pablos, 2015; Pomeroy et al.).

Homo floresiensis did not develop a CFNB and the cuneiform surfaces are smaller in proportion to other mentioned species (Jungers et al.). The navicular is the most primitive in shape to the genus Homo, which was not available to a high-speed or efficient running. The morphology of the locomotor skeleton of $\mathrm{H}$. floresiensis exhibits features of a biped hominid but not exactly like the modern human.

In relation to ancient Homo sapiens, the presence of CFNB was estimated at $36.4 \%$ in Early/Mid Upper Paleolithic humans, and $100 \%$ in Middle Paleolithic Modern Humans (Trinkaus et al.). In contrast, Late Pleistocene $H$. sapiens $54.6 \%$ of CFNB (Pablos et al.).

Because of bipedalism, joints of hominin foot became less mobile and the navicular bone developed an essential task in the movement of feet. It is especially important for the articulation between the talar head and the talar facet of the navicular, by being part of the peritalar joint complex (subtalar joint and partially the articulation of Chopart). This is one of the most mobile zones of the foot. The navicular bone has developed morphological changes such as the reduction of the tuberosity and the CFNB (Prang), which is absent in a large numbers of modern humans. However, the foot structure of non-human primates developed a different mobile configuration, allowing the use of the foot as a grasping tool, which is an important adaptation in arboreal environments. Their foot must be able to rotate inwards and towards the curved surface of a branch while grasping and/ or vertical climbing. These movements require that navicular and cuboid rotate laterally together (Gebo, 2014) creating a contact between them, forming the CFNB. Also taking part in these movements are strong supinator muscles, the movement of the subtalar joint (talocalcaneal joint) and, the transverse tarsal joint (articulation of Chopart).

The CFNB shows variability among different primate groups. The strepsirhine suborder, predominantly arboreal, quadrupeds, leaping/vertical clinging, show a broad area of articulation with a cuboid facet next to the ectocuneiform and mesocuneiform facets (Dagosto, 1988). This could explain a better adaptation to facilitate the grasp movement. Nonetheless, it is not clear if this strepsirhine condition is a derived character shared exclusively by these taxa (Fleagle \& Key, 1994). For instance, in Archaeolemur and Daubentonia CFNB is located more laterally than toothcombed lemurs, being the medial lies in the union of the ecto and mesocuneiform facets (Sargis \& Dagosto, 2008). In contrast, CFNB of omomyids, tarsiers and anthropoids that use diverse locomotion, including permanent bipedalism in humans, is related to the ectocuneiform facet and does not spread to the mesocuneiform facet nor the lateral edge (Dagosto; Fleagle \& Key; Ni et al., 2013). In primates, all the phalanges and the entocuneiform (especially for its saddle-shape joint with the hallux) are involved in the grasp movement. Sarmiento \& Marcus claim that a large cuboid 
facet would be involved in supinated postures, commonly performed by great apes in vertical climbing. For example, the relative big cuboid facet exhibit by African apes and Hadar specimens (AL-333) could be related to hallucal opposability.

However, the feet of modern humans show different biomechanical properties affecting CFNB. For instance, there is a "locking" in the articulation of Chopart that works as a rigid structure, transferring the force effectively during pushoff. This could be due by the plantar flange projecting from the cuboid in articulation with the calcaneus and the plantar ligaments (Lovejoy et al., 2009; Crompton et al., 2012; Prang). Thus, in the propulsive phase of gait, the foot becomes rigid, acting as a lever; meanwhile in the stance phase of walking, the human foot is flexible and adaptable to the ground through the cushing joints (DeSilva \& Gill, 2013). This locking restricts CFNB development. Specifically a strong interosseous ligament binds navicular and cuboid bones, blocking the rotation and avoiding the collapse of the mid-transverse arch under load (Gomberg, 1985).

Sarmiento \& Marcus explained that reduced CFNB or even its absence in modern humans reflects a foot with a tendency to pronate. Biomechanically, it could be explained as a foot loaded parallel to its long axis and rarely exposed to large midlateral forces. However, in our analysis of the human step with X-ray cinematography from normofunctional individuals, we found no significant differences in the contact of both bones during all the phases of the gait. The presence or absence of CFNB seems to not affect the normal step. This fact could explain why no homogenous frequencies were found in different ancient human and recent series.

Therefore, the differences of CFNB frequency shown in the historical series could be due to other factors such as geographical conditions, genetics, stressful activities and cultural uses, such as footwear use or barefoot conditions. For instance, inadequate shoes can produce deformity (Frey et al., 1993; Bálint et al., 2003), altering the normal gait and quality of life.

The presence of the CFNB could also be relate to some measurements of the midtarsal bones. The sagittal length of the talar facet (LSAGTAL) is the only variable that shows significant differences ( $p>0.05$ ) among different bones, with or without the CFNB. This measurement affects the talo-navicular joint, one of the most important on the midfoot. This ball and socket articulation mainly allows movements of gliding and rotation, with a closed packed position to the supination (Magee, 2008). One of these movements, which involves the sagittal length of the talar facet, may be responsible for producing the contact between the navicular and cuboid (as we observed in the X-ray cinematography analysis). The force of the talar head during the screw-like movement produced in the subtalar joint could push the medial or lateral area of the talar facet (Louie et al., 2014). If this impact is mainly in the medial area of the navicular, this bone could increase the contact with a rigid cuboid, which may produce a CFNB.

Taking all data into consideration, the evolution of the foot indicates that CFNB is produced by the movements related to the talar facet, possibly for a mild but constant and incomplete supination of the foot.

Summarizing, our results show that the total frequency of the presence of the cuboid facet is $52.7 \%$, without significant differences among populations and between sexes. Morphometrically, the sagittal length of the talar facet of the navicular (LSAGTAL) is the only one dimension related to the presence of the cuboid facet. Considering the movements in which the talar facet is involved, the position of the talo-navicular joint, could produce the contact between the cuboid and navicular, creating the facet.

In addition, taking into account the evolutionary history of the primate foot, the presence of CFNB should be related with supination movements that, in primates with a grasping foot, lead to a big cuboid facet. In correspondence to the above-mentioned data, the absence or small size of this structure in modern humans could be understood as the functionality and biomechanical of the gait. Otherwise, factors like footwear, geographical conditions, genetics, or stressful activities have an impact in the frequencies among different populations.

ACKNOWLEDGEMENTS. We would like to thank to Carlos García Mallo from HUSC for the X-ray cinematography analysis; to the professors: José Antonio Sanchez from the Department of Toxicology and Sanitary Legislation of UCM; Alfonso Rodriguez from the Faculty of Medicine of UAB; Miguel Botella and Inmaculada Alemán from Department of Legal Medicine, Toxicology and Anthropology of UGr; and to Antonio Moro from the Museum de Terrassa, for permitting the access to the documented and archaeological collections of Madrid, Barcelona, Granada and Esglésies de Sant Pere. Finally, we sincerely thank to Ana María Martinez, Joesephina Saager and Bernardo Vila for proofreading this text in English; and to CONICYT PAI/2014-73130722 (ES) for their financial support. The authors are members of 2017SGR1630 of the Generalitat de Catalunya, Spain. 
SALDÍAS, E.; MALGOSA, A.; JORDANA, X. \& ISIDRO, A. Implicaciones morfológicas y biomecánicas de la faceta cuboídea del navicular en la marcha. Int. J. Morphol., 37(4):1397-1403, 2019.

RESUMEN: La faceta cuboídea del hueso navicular es una carilla plana e irregular, presente en primates no humanos y en algunos de nuestros ancestros. En humanos modernos, no siempre está presente y es descrita como "un hallazgo ocasional" por la bibliografía. Hasta la fecha, no hay suficientes datos acerca de su incidencia en poblaciones antiguas y contemporáneas, ni una explicación biomecánica sobre su presencia o ausencia. El objetivo de nuestro estudio fue evaluar la frecuencia de la faceta cuboídea en poblaciones recientes y antiguas, su relación con las dimensiones de los huesos tarsales y su rol en la biomecánica de la marcha. Fueron estudiados 354 pares de naviculares y otros huesos del tarso provenientes de colecciones osteológicas de Cataluña, España. Aplicamos nueve medidas aplicadas al talus, navicular y cuboides para corroborar su relación con la presencia de la faceta. Para analizar sus parámetros biomecánicos, se empleó X-ray cinematography en pacientes hospitalarios. Los resultados mostraron que alrededor de un $50 \%$ de los individuos desarrollaron esta carilla, sin diferencias entre sexos o series. Además, observamos que la longitud sagital de la faceta talar (LSAGTAL) es mayor en aquellas muestras con faceta cuboídea. No hay diferencias significativas en el contacto de los huesos en ninguna de las fases de la marcha. Después de revisar su presencia en primates no humanos, su implicancia en el bipedismo y en la marcha moderna, sugerimos que la faceta cuboídea podría estar relacionada con el tamaño de la faceta talar y la posición de la articulación talo-navicular. Sin embargo, otros factores como las condiciones geográficas, genética y stress ocupacional también podrían afectar su presencia.

PALABRAS CLAVE: articulación cuboideonavicular; variabilidad poblacional; faceta talar; movimiento de supinación.

\section{REFERENCES}

Bálint, G. P.; Korda, J.; Hangody, L. \& Bálint, P. V. Regional musculoskeletal conditions: foot and ankle disorders. Best Pract. Res. Clin. Rheumatol., 17(1):87-111, 2003.

Clarke, R. J. \& Tobias, P. V. Sterkfontein member 2 foot bones of the oldest South African hominid. Science, 269(5233):521-4, 1995.

Crompton, R. H.; Pataky, T. C.; Savage, R.; D'Août, K.; Bennett, M. R.; Day, M. H.; Bates, K.; Morse, S. \& Sellers, W. Human-like external function of the foot, and fully upright gait, confirmed in the 3.66 million year old Laetoli hominin footprints by topographic statistics, experimental footprint-formation and computer simulation. J. R. Soc. Interface, 9(69):707-19, 2012.

Dagosto, M. Implications of Postcranial Evidence for the Origin Of Euprimates. In: Strasser, E. \& Dagosto, M. (Eds.). The primate Postcranial Skeleton. New York, Academic Press, 1988. pp.47-53.

DeSilva, J. M. \& Gill, S. V. Brief communication: a midtarsal (midfoot) break in the human foot. Am. J. Phys. Anthropol., 151(3):495-9, 2013.

Fleagle, J. \& Key, R. Anthropoid Origins. New York, Springer US, 1994.

Frey, C.; Thompson, F.; Smith, J.; Sanders, M. \& Horstman, H. American Orthopaedic Foot and Ankle Society women's shoe survey. Foot Ankle, 14(2):78-81, 1993.
Gebo, D. Musculo Skeletal System. In: Gebo, D. L. \& Severson, M. (Eds.). Primate Comparative Anatomy. Baltimore, John Hopkins University Press, 2014. pp.57-9.

Gomberg, D. Form and Function of the Hominoid Foot. Massachusetts, University of Massachusetts, 1981.

Gomberg, D. N. Functional differences of three ligaments of the transverse tarsal joint in Hominoids. J. Hum. Evol., 14(6):553-62, 1985.

Jungers, W. L.; Harcourt-Smith, W. E.; Wunderlich, R. E.; Tocheri, M. W.; Larson, S. G.; Sutikna, T.; Due, R. A. \& Morwood, M. J. The foot of Homo floresiensis. Nature, 459(7243):81-4, 2009.

Kidd, R. S.; O'Higgins, P. \& Oxnard, C. E. The OH8 foot: a reappraisal of the functional morphology of the hindfoot utilizing a multivariate analysis. J. Hum. Evol., 31(3):269-91, 1996.

Louie, P. K.; Sangeorzan, B. J.; Fassbind, M. J. \& Ledoux, W. R. Talonavicular joint coverage and bone morphology between different foot types. J. Orthop. Res., 32(7):958-66, 2014.

Lovejoy, C. O.; Suwa, G.; Spurlock, L.; Asfaw, B. \& White, T. D. The pelvis and femur of Ardipithecus ramidus: the emergence of upright walking. Science, 326(5949):71e1-6, 2009.

Magee, D. J. Lower Leg, Ankle and Foot. In: Magee, D. J. (Ed.). Orthopedic Physical Assessment. $6^{\text {th }}$ ed. St. Louis (MO), Saunders Elsevier, 2008. pp.847.

Manners-Smith, T. A study of the navicular in the human and anthropoid foot. J. Anat. Physiol., 41(Pt. 4):255-79, 1907.

Ni, X.; Gebo, D. L.; Dagosto, M.; Meng, J.; Tafforeau, P.; Flynn, J. J. \& Beard, K. C. The oldest known primate skeleton and early haplorhine evolution. Nature, 498(7452):60-4, 2013.

Pablos, A. The Foot in the Homo fossil record. Mitt. Ges. Urgesch., 24:1128, 2015.

Pablos, A.; Sala, N. \& Arribas, A. Taxonomic reassignment of the Paleolithic human navicular from Cueva de los Torrejones (Guadalajara, Spain). Archaeol. Anthropol. Sci., 10(8):1867-80, 2018.

Pomeroy, E.; Mirazón Lahr, M.; Crivellaro, F.; Farr, L.; Reynolds, T.; Hunt, C. O. \& Barker, G. Newly discovered Neanderthal remains from Shanidar Cave, Iraqi Kurdistan, and their attribution to Shanidar 5. J. Hum. Evol., 111:102-18, 2017.

Prang, T. C. Reevaluating the functional implications of Australopithecus afarensis navicular morphology. J. Hum. Evol., 97:73-85, 2016.

Sargis, E. J. \& Dagosto, M. (Eds.). Mammalian Evolutionary Morphology. A Tribute to Frederick S. Szalay. Heidelberg, Springer Netherlands, 2008.

Sarmiento, E. E. \& Marcus, L. F. The os Navicular of Humans, Great Apes, $\mathrm{OH} 8$, Hadar, and Oreopithecus. Function, Phylogeny, and Multivariate Analysis. Am. Mus. Novit, (3288):1-38, 2000.

Trinkaus, E. A Functional Analysis of the Neandertal Foot. Philadelphia (PA), University of Pennsylvania, 1975.

Trinkaus, E.; Wojtal, P.; Wilczynski, J.; Sázelová, S. \& Svoboda, J. Palmar, patellar, and pedal human remains from Pavlov. PaleoAnthropology, 2017:73-101, 2017.

Corresponding author:

Dr. Albert Isidro

Orthopedic and Trauma Surgery Department

Hospital Universitari Sagrat Cor

Carrer de Viladomat, 288

08029 Barcelona

SPAIN

E-mail: aisidro.cot@gmail.com

Received: 30-03-2019 Accepted: 17-06-2019 